\title{
Special Investigation of Developmental of Mandibular Asymmetry and Imbalance Body Posture: A Literature Review
}

\author{
Ervina Sofyanti $^{1 *}$, Trelia Boel $^{2}$, Denny Satria ${ }^{3}$ \\ ${ }^{1}$ Department of Orthodontics, Faculty of Dentistry, Universitas Sumatera Utara, Medan, Indonesia; ${ }^{2}$ Department of \\ Dentomaxillofacial Radiograph, Faculty of Dentistry, Universitas Sumatera Utara, Medan, Indonesia; ${ }^{3}$ Department of \\ Pharmaceutical Biology, Faculty of Pharmacy, Universitas Sumatera Utara, Medan, Indonesia
}

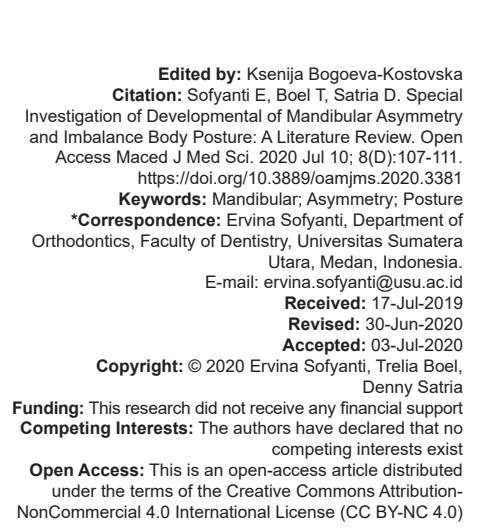

Abstract

BACKGROUND: Previous studies have reported comprehensive visions about the correlation between the development of dentofacial problems and postural disorder. Mostly of dentofacial issues related to mandibular asymmetry, which can lead to erroneous treatment plans that end in frustration for both patient and orthodontist.

AIM: This paper aims to describe some evidence bases dentistry of malocclusions with asymmetry in mandibular and trunk.

METHODS: We used different electronic databases such as PubMed Health and Google Scholar with specific keywords such as development mandibular asymmetry, trunk asymmetry, and body posture asymmetry. In this preliminary study, the term of imbalance body posture leads to trunk and body posture asymmetry.

RESULTS: Most of the studies reported the involvement of temporomandibular disorder in those asymmetries. We assumed the necessity for considering development asymmetry in an examination and should be regarded as a particular investigation procedure in orthodontic treatment.

CONCLUSION: However, the limitation in understanding the developmental asymmetries in determining the etiology and risk factor of development mandibular asymmetry and imbalanced body posture require special investigation.

\section{Introduction}

The timing of the pubertal growth spurt is paramount in planning orthodontic treatment since the general growth and development influence orthodontic treatment prognosis. In human skeletal growth, the skeletal basis of the postural is usually developed at the same age as well as mandibular growth and development [1], [2]. The symmetry assessment becomes a key determinant for assessing expressions and attractiveness in psychology and anthropology nowadays, including facial and body posture. Design and diagnostic techniques in solving the mystery of development asymmetry that includes dental, craniofacial, and body posture are limited; the world of gnathology is required to increase the interdisciplinary approach.

It is difficult to define which point of normal asymmetry becomes abnormal. The sense of balance and imbalance of clinicians and patients is often determined. There was generalized asymmetry of the face and body with the left-sided predominance in the evaluation of the lateral nose, face, and body as a new finding [3]. In dentistry, a significant facial asymmetry may negatively affect the development of orofacial, nutritional, and psychosocial caused functional problems and aesthetic [4], [5], [6]. Comprehensive evaluations of asymmetries might be one of great helps for the physicians, physiotherapists, and dentists for every precise diagnosis and thus selecting the best possible functional rehabilitation techniques.

Previous studies have reported some comprehensive visions between the development of dentofacial problems and postural disorder. However, the amount of dentists that was able to diagnose the occlusal disease and of those who diagnose many people resort to aggressive treatment modalities is still limited. Some compensation mechanisms were occurring within the neuromuscular system regulating body balance [7]. Patients with facial asymmetry usually exhibit compensatory head posturing due to which the head is tilted slightly to the right or left to compensate for the effect of asymmetry. Therefore, clinicians should deliberately orient the patient's head to correct any compensatory head posture before making a proper objective and quantitative examinations. The patient is also advised to eliminate other compensatory mechanisms such as mannerisms and hairstyles that might mask the asymmetric deformity, thus misleading the treatment plan [5]

By understanding the relationship between the stomatognathic system and body posture, we 
can improve the muscular-skeletal disorders that are associated with temporomandibular joint (TMJ) disorders, occlusal changes, and tooth loss [8]. Further researches also establish a direct link between poor posture and temporomandibular disorder (TMD) that is required to obtain proper function, improve aesthetics, and stability [9]. Although there are no particular conclusions in some associations between the cephalometric variables and the surface electromyography activity of the head, neck, and trunk muscles, there was a possible mechanism concerning these results and requires longitudinal studies in the future. Hence, the objective of this paper is to investigate malocclusions with asymmetry in mandibular and trunk due to the multifactorial of asymmetry and homeostasis of human beings, especially in facial and posture.

\section{Methodology}

All published articles were obtained in electronic databases like PubMed Health and Google Scholar. The search keywords included mandibular development asymmetry, trunk asymmetry, and body posture asymmetry.

\section{Mandibular asymmetry}

A previous study conducted in 1460 patients at the University of North Carolina reported that the most remarkable feature with facial asymmetry is the deviation of the chin [10].

To understand the multifactorial of mandibular asymmetry, a thorough, methodical diagnostic approach is essential for the appropriate management of patients presenting with dentofacial asymmetry [11]. In orthodontics, we can anticipate difficulties with kinds of treatments if we understand the concepts of symmetry and thoroughly well informed about the complexity of craniofacial growth. The management of patients presenting with a mandibular asymmetry that is focusing mainly on the treatment of developmental asymmetries is a prime diagnostic in orthodontic treatment nowadays [12].

Mandibular asymmetry has an embryological origin. The facial bones morphogenesis is the climax of complicated mechanisms that occur between the $4^{\text {th }}$ and $10^{\text {th }}$ week in the life of the embryo. A malfunction of the mechanisms of cellular migration, cellular differentiation, or apoptosis can compromise these processes and lead to malformations [13]. The difficulty in treating any malocclusion with dentofacial deformity is because it is the most prevalent among showed vertical growth patterns [10]. Unilateral vertical maxillary excess and mandibular asymmetry are usually related to an occlusal cant. This explains why dental practitioners are not able to treat most asymmetries single-jaw surgery only [14]. Since the development asymmetry is a complex and multifactorial phenomenon, dental literature seldom addresses facial asymmetry despite being highly prevalent in the overall population. The limitation of epidemiological studies, as well as histological and genetic research aiming at the determination of the etiology and the risk factors, should be advised in the future [15].

\section{Imbalance body posture}

Body posture is defined as the result of the relationship between proximal segments of the body and the interconnections between all parts composing the human body or a term that related to the asymmetry of the halves of a human body. From a theoretical viewpoint, the ideal posture is the condition in which all structures combine their work to maintain static and dynamic balance with maximum efficiency and minimal overload and energy expense. On the contrary, poor posture is seen as a faulty relationship between the different body segments, requesting an increased demand for adaptation to the support structures and decreased equilibrium efficiency [16]. The imbalanced body posture identic with trunk imbalance or asymmetry and postural disorder as the phenotype of scoliosis. These anomalies are varied in transversal, vertical, and sagittal [17].

\section{Mandibular asymmetry and imbalance body posture}

The symmetry of craniofacial structures remains unaffected by moderate trunk asymmetry in young adults [18]. While correlations between jaw position and body posture for the cervical spine can exist, there was a postural compensatory mechanism that leads to mitigating the effects of jaw position and body posture for the cervical spine in the general population [19]. Visual perception control is most important in orienting the head in the frontal plane in the Swedish young adults, with moderate trunk asymmetry and the head position maintained by cervical spine adaption. However, there was a significant difference between patients with a skeletal horizontal-vertical facial axis and patients with a basal distal-mesial position for the facial depth in pelvic torsion [20].

There were pieces of plausible evidence for an increased prevalence of unilateral Angle Class II malocclusions that are associated with scoliosis, and an increased risk of malocclusions such as lateral crossbite and midline deviation is apparent in children affected by scoliosis. Then, the improvement of some documentation regarding associations between a 
reduced range of lateral movements and scoliosis seems convincing because it also mentioned the association between plagiocephaly and scoliosis [21], [22]. Previous studies reported the trunk asymmetry and postural disorder as the phenotype of scoliosis. There was a more frequent and severe dentofacial deviation in the spinal dysfunction with Scheuermann's disease than scoliosis children. Caution of early detection was required from an orthodontics point of view [23]. In the correlation analysis, the ramus length difference and anterior nasal spine-menton angle had a possible correlation with the coracoid height difference, clavicular angle, radiographic shoulder height, and clavicle-rib intersection difference $(P<0.05)$ [24].

The degree of mandibular deviation has a high correlation with the degree of scoliosis and trunk imbalance in a case-control study of the adult population. There was a linear trend in the degree of scoliosis and shoulder imbalance correlated with the degree of mandibular deviation. The direction of mandibular deviation was the same as that of the lateral bending of the thoracolumbar vertebrae, which was the opposite to the direction of lateral bending of cervical vertebrae [25]. Genetically, there was no significant correlation between clinical parameters vertical mandibular symmetry and scoliosis symptoms in a genomic study of IGF-1 [26].

There was a well-preserved postural balance in the presence of TMJ internal derangement that related to mandibular asymmetry should be considered in potential influence the whole-body posture that leads to TMD and vice versa. There was no feature of any peculiar changes in body posture [27]. Conversely, changing body posture affected mandibular position in asymptomatic subjects between 21 and 53 years old [28].

\section{Malocclusion and imbalance body posture}

The evaluation of postural body stability and malocclusions in different skeletal patterns of orthodontic patients showed decreased balance and increased sway based on malocclusion severity. Then a significant increase in sway area and sway velocity postural parameters in body posture stability between subjects with myogenic TMD compared to healthy controls [29], [30]. The study concludes that malocclusion is associated with the posture of the changes, since the balance, only two studies presented this outcome and was in a considered positive for the worsening of static equilibrium, but with no clinical application, and another positive for improving dynamic balance [31]. The more extended treatment of the malocclusions closely correlated to postural disorders in children with spinal disorders [23]. However, there were claims of an association between body posture and dental occlusion in growing subjects that should be discarded based on epidemiological observations among 12-year-old children in Italy [32].
The existence of clinically relevant correlations between malocclusion traits and body posture in population age range 10.6-16.3 years old among local sports subjects based on posturography as a diagnostic aid was not suggested [33]. However, it differs from another study that reported that the sway area seems to be the most sensitive parameter for evaluating the effect of occlusion on body posture in healthy subjects [34].

\section{Discussion}

The individual's postural position can suffer biomechanical alterations due to stomatognathic alterations. This condition causes clinically visible changes in dysfunctional individuals and affecting the performance of the involved structures, including TMJ, cervical, spinal, and leg that lead to body posture [35], [36]. However, there were limited scientific pieces of evidence to support an overview of preventing postural imbalances or alteration of spine curvatures by performing occlusal and/or orthodontic treatment, although there are some reports about associations between occlusal factors and postural alterations [37].

This issue is essential since all gnathological athletes should be analyzed individually and carefully with clinical and instrumental analyses to examine the possible real effectiveness of an occlusal splint to improve the postural structure and sports performance [38]. Trunk asymmetry, as well as the skeletal basis of the postural disorders, developed in a similar age of mandibular growth. By including postural considerations in orthodontic diagnosis at the final analysis, it will lead to a complete corporal analysis in mandibular asymmetry in addressing the clinical approach integrating treatment of corporal posture into orthodontic care [39]. Then, only $21 \%$ among practitioners in India were aware of the interdisciplinary approach in treating patients with severe malocclusion, TMD, musculoskeletal, myofascial pain, and body posture [40]. The role of TMJ position where the head and oral function located and on the posture on the body posture where the abnormal head position may alter biomechanical skull-neck and skull-mandibular relationship, influencing growth and the body posture of the individual [41].

The most present study reviewed literature studies about the relationship between wrong posture and TMD. Postural shifts, such as the anterior displacement of the head, increased cervical lordosis, and lack of shoulder leveling, usually happened to patients with TMD [42]. However, the variance of body posture disorder that leads to the poor methodological quality of analysis can explain for the weak evidence observed [43]. A further systematic review and longitudinal researches are required to understand the 
causal relationship between postural abnormalities and mandibular asymmetry causal relationship between body postural and mandibular asymmetry.

\section{Conclusions}

Most studies reported that TMD involved and contributed to these phenomenon asymmetries. We assumed the necessity for considering development asymmetry in the examination and should be regarded as a particular investigation procedure in orthodontic treatment. However, to cover the limitation in understanding the developmental asymmetries, a special investigation will be required in determining the etiology and the risk for development mandibular asymmetry and imbalanced posture.

\section{Acknowledgments}

We want to thank the Ministry of Research, Technology, and Higher Education through Penelitian Dasar Unggulan Perguruan Tinggi: Grant No.11/E1/ KP.PTNBH/2019.

\section{References}

1. Mellion JZ, Behrents RG, Johnston LE Jr. The pattern of facial skeletal growth and its relationship to various common indexes of maturation. Am J Orthod Dentofacial Orthop. 2013;143(6):845-54. https://doi.org/10.1016/j. ajodo.2013.01.019

PMid:23726335

2. Sharma P, Arora A, Valiathan A. Age changes of jaws and soft tissue profile. ScientificWorldJournal. 2014;2014:301501. https://doi.org/10.1155/2014/301501

PMid:25506064

3. Hafezi F, Javdani A, Naghibzadeh B, Ashtiani AK. Laterality and left sidedness in the nose, face, and body: A new finding. Plast Reconstr Surg Glob Open. 2017;5(12):e1590. https://doi. org/10.1097/gox.0000000000001590 PMid:29632770

4. Bishara SE, Burkey PS, Kharouf JG. Dental and facial asymmetries: A review. Angle Orthod. 1994;64(2):89-98. PMid:8010527

5. Srivastava D, Singhb H, Mishraa S, Sharmab P, Kapoorb $P$, Chandraa L. Facial asymmetry revisited: Part I-diagnosis and treatment planning. J Oral Biol Craniofac Res. 2018;8(1):7-14. PMid:29556456

6. Choi KY. Analysis of facial asymmetry. Arch Craniofac Surg. 2015;16(1):1-10.

PMid:28913211
7. Manfredini D, Castroflorio T, Perinetti G, Guarda-Nardini L. Dental occlusion, body posture, and temporomandibular disorders: Where we are now and where we are heading for. J Oral Rehabil. 2012;39(6):463-71. https://doi. org/10.1111/j.1365-2842.2012.02291.x PMid:22435603

8. Cuccia A, Caradonna C. The relationship between the stomatognathic system and body posture. Clinics (Sao Paulo). 2009;64(1):61-6. https://doi.org/10.1590/ s1807-59322009000100011

PMid:19142553

9. Pacella E, Dari M, Giovannoni D, Mezio M, Caterini L, Costantini A, et al. The relationship between occlusion and posture: A systematic review. Webmed Centr Orthod. 2017;8(11):WMC005374.

10. Severt TR, Profitt WR. The prevalence of facial asymmetry in the dentofacial deformities population at the university of North Carolina. Int J Adult Orthodon Orthognath Surg. 1997;12(3):171-6. PMid:9511487

11. Brionne C, Cadre B, Laroche $\mathrm{Y}$, Lhotellier J, Maze M, Raffre A, et al. The diagnosis of mandibular asymmetries. Rev Orthop Dento Faciale. 2013;16:302. https://doi.org/10.1051/ odf/2013202

12. Chia SY, Naina FB, Gill DS. The etiology, diagnosis and management of mandibular asymmetry. Ortho Update. 2008;1(1):44-52.

13. Lin $\mathrm{H}$, Zhu $\mathrm{P}$, Lin $\mathrm{Y}$, Wan $\mathrm{S}$, Shu $\mathrm{X}, \mathrm{Xu} \mathrm{Y}$, et al. Mandibular asymmetry: $A$ three-dimensional quantification of bilateral condyles. Head Face Med. 2013;9:1-7. https://doi. org/10.1186/1746-160x-9-42

PMid:24354862

14. Cheong YW, Lo LJ. Facial asymmetry: Etiology, evaluation, and management. Chang Gung Med J. 2011;34(4):341-51. PMid:21880188

15. Thiesen G, Gribel BF, Freitas MP. Facial asymmetry: A current review. Dental Press J Orthod. 2015;20(6):110-25. https://doi. org/10.1590/2177-6709.20.6.110-125.sar PMid:26691977

16. Gonzalez HE, Manns A. Forward head posture: Its structural and functional influence on the stomatognathic system, a conceptual study. Cranio. 1996;14(1):71-80. https://doi.org/10. 1080/08869634.1996.11745952 PMid:9086879

17. Sislauskiene M, Smailiene D, Lopatiene K, Cekanauskas E, Ruta P, Sidlauskas M. Relationship between malocclusion, body posture, and nasopharyngeal pathology in pre-orthodontic children. Med Sci Monit. 2015;21:1765-73. https://doi. org $/ 10.12659 / \mathrm{msm} .893395$ PMid:26086193

18. Zepa I, Hurmerinta $K$, Kovero $O$, Nissinen $M$, Könönen $M$, Huggare J. Trunk asymmetry and facial symmetry in young adults. Acta Odontol Scand. 2003;61(3):149-53. https://doi. org/10.1080/00016350310001695

PMid: 12868688

19. Arienti C, Villafañe JH, Donzelli S, Zaina F, Buraschi R, Negrini S. Trunk, and craniofacial asymmetry are not associated in the general population: A cross-sectional study of 1029 adolescents. Eur J Med Res. 2017;22(1):36. https://doi. org/10.1186/s40001-017-0280-y

PMid:28962640

20. Lippold C, Moiseenko T, Drerup B, Schilgen M, Vegh A, Danesh G. Spine deviations and orthodontics treatment of asymmetry malocclusion in children. BMC Musculoskelet Disord. 2012;13(1):151-8. https://doi.org/10.1186/1471-2474-13-151 PMid:22906114 
21. Huggare J. Postural disorder and dentofacial morphology. Acta Odontol Scand. 1998;56(6):385-86.

PMid:10066122

22. Saccucci M, Tettamanti L, Mummolo S, Polimeni A, Festa F, Tecco S. Scoliosis and dental occlusion: A review of the literature. Scoliosis. 2011;6:15. https://doi.org/10.1186/1748-7161-6-15 PMid:21801357

23. Segatto $E$, Lippold $C$, Végh A. Craniofacial features of children with spinal deformities. BMC Musculoskelet Disord. 2008;9:169. https://doi.org/10.1186/1471-2474-9-169

PMid: 19102760

24. Hong JY, Suh SW, Modi HN, Yang JH, Hwang YC, Lee DY, et al. Correlation between facial asymmetry, shoulder imbalance, and adolescent idiopathic scoliosis. Orthopedics. 2011;34(6):187. https://doi.org/10.3928/01477447-20110427-14 PMid:21667906

25. Zhou S, Yan J, Da H, Yang Y, Wang N, Wang W, et al. A correlational study of scoliosis and trunk balance in adult patients with mandibular deviation. PloS One. 2013;8(3):e59929. https://doi.org/10.1371/journal.pone.0059929

PMid:23555836

26. Sofyanti E, Siregar DI, Siregar O, Boel T, Satria D, Tann G. Identification of single nucleotide polymorphism insulin-like growth factor Type 1 gene in vertical mandibular asymmetry patients with idiopathic scoliosis symptom. Asian J Pharm Clin Res. 2018;11(1):100-3. https://doi.org/10.22159/ajpcr.2018. v11s1.26686

27. Rocha T, Castro MA, Guarda-Nardini L, Manfredini D. Subjects with temporomandibular joint disc displacement do not feature any peculiar changes in body posture. J Oral Rehabil. 2017;44(2):81-8. https://doi.org/10.1111/joor.12470 PMid:27973713

28. Sakaguchi K, Mehta NR, Abdallah EF, Forgione AG, Hirayama $H$, Kawasaki $\mathrm{T}$, et al. Examination of the relationship between mandibular position and body posture. Cranio. 2007;25(4):23749. https://doi.org/10.1179/crn.2007.037 PMid: 17983123

29. Arumugam $\mathrm{P}$, Padmanabhan $\mathrm{S}$, Chitharanjan $\mathrm{AB}$. The relationship of postural body stability and severity of the malocclusion. APOS Trends Orthod. 2016;6(4):205-10. https:// doi.org/10.4103/2321-1407.186436

30. Nota A, Tecco S, Ehsani S, Podulo J, Baldini A. Postural stability in subjects with temporomandibular disorder and healthy controls: A comparative assessment. J Electromyogr Kinesiol. 2017;37:21-4. https://doi.org/10.1016/j.jelekin.2017.08.006 PMid:28865312

31. Stancker TG, Silva AC, Neto HP, Rodrigues CD. Malocclusion influence on balance and posture: A systematic review. Man Ther Posturol Rehab J. 2015;13:015. https://doi.org/10.17784/ mtprehabjournal.2015.13.320

32. Perillo L, Signoriello G, Ferro F, Baccetti T, Masucci C, Apicella D, et al. Dental occlusion and body posture in growing subjects.
A population-based study in 12 years old Italian adolescents. Int Dent SA. 2008;10(6):46-52.

33. Perrinetti G, Contardo L, Biavati AS, Perdoni L, Castaldo A Malocclusion and body posture in young subjects: A multiple regression study. Clinics (Sao Paulo). 2010;65(7):689-95. https://doi.org/10.1590/s1807-59322010000700007 PMid:20668626

34. Baldini, A, Nota A, Tripodi D, Longoni S, Cozza P. Evaluation of the correlation between dental occlusion and posture using a force platform. Clinics (Sao Paulo). 2013;68(1):45-9. https://doi. org/10.6061/clinics/2013(01)oa07

PMid:23420156

35. Strini PJ, Machado NA, Gorreei MC, Ferreira A, Sousa G, Neto AJ. Postural evaluation of patients with temporomandibular disorders under the use of occlusal splints. J Appl Oral Sci. 2009;17(5):539-43. https://doi.org/10.1590/ s1678-77572009000500033

PMid:19936539

36. Salkar RG, Radke UM, Deshmukh SP, Radke PM. Relationship between temporomandibular joint disorders and body posture. Int J Dent Health Sci. 2015;2(6)1523-30.

37. Michelotti A, Buonocone G, Manzo P, Pelegrino G, Farella M. Dental occlusion and posture: An overview. Prog Orthod. 2011;12(1):53-8.

PMid:21515232

38. Baldini A, Beraldi A, Nota A, Danelon F, Ballanti F, Longoni S. Gnathological postural treatment in a professional basketball player: A case report and an overview of the role of dental occlusion on performance. Ann Stomatol (Roma). 2012;3(2):51-8.

PMid:23087786

39. Amat P. Occlusion and posture: Facts and beliefs. J Dentofacial Anom Orthod. 2008;11:186-211. https://doi.org/10.1051/ odfen/2008030

40. Joshi NM, Kulkarni AD, Srichand R. Evaluation of the knowledge regarding correlation between body posture, pain, and occlusion amongst the practicing dentist of navi Mumbai-questionnairebased study. IJOCR. 2015;3(4):21-4.

41. Pruneda JF. Dental Malocclusion and its relationship with body posture: A new research challenge in stomatology. Bol Med Hosp Infant Mex. 2013;70(5):341-3.

42. Amantea DV, Novaes AP, Campolongo GD, Barros TP. The importance of the postural evaluation in a patient with temporomandibular joint dysfunction. Acta Ortop Bras. 2004;12(3):155-9. https://doi.org/10.1590/ s1413-78522004000300004

43. Chaves TC, Turci AM, Pinheino CF, Sousa LM, Grossi DB. Static body posture misalignment in an individual with temporomandibular disorder: A systematic review. Braz J Phys Ther. 2014;18(6):481-501. https://doi.org/10.1590/ bjpt-rbf.2014.0061

PMid:25590441 